\title{
Relative importance of different dispersal vectors for small aquatic invertebrates in a rock pool metacommunity
}

\author{
Bram Vanschoenwinkel, Saïdja Gielen, Hanne Vandewaerde, Maitland Seaman and \\ Luc Brendonck
}

B. Vanschoenwinkel (bram.vanschoenwinkel@bio.kuleuven.be), S. Gielen, H. Vandewaerde and L. Brendonck, Laboratory of Aquatic Ecology and Evolutionary Biology, Katholieke Univ. Leuven, Ch. Deberiotstraat 32, BE-3000 Leuven, Belgium. - M. Seaman, Centre for Environmental Management, Univ. of the Free State, Mandela Drive, ZA-9300 Bloemfontein, South Africa.

\begin{abstract}
The extent and frequency of passive overland dispersal of freshwater invertebrates as well as the relative importance of different dispersal vectors is not well documented. Although anecdotal evidence subscribing the feasibility of individual vectors in various aquatic systems is abundant, dispersal rates have rarely been quantified for different vectors in one study system. Earlier studies also usually investigated dispersal potential rather than actual dispersal rates. In this study we have estimated passive dispersal rates of invertebrate propagules within a cluster of temporary rock pools via water, wind and amphibians in a direct way. Overflows after heavy rains mediated dispersal of a large number of propagules through eroded channels between pools, which were collected in overflow traps. Taking into account model based predictions of overflow frequency, this corresponds with average dispersal rates of 4088 propagules/channel $\mathrm{yr}^{-1}$. Wind dispersal rates as measured by numbers of propagules collected on sticky traps mounted between pool basins were very high (average dispersal rate: 649 propagules $\mathrm{m}^{-2}$ in one month) and were positively related to the proximity of source populations. Finally, invertebrate propagules were also isolated from the faeces of African clawed frogs Xenopus laevis caught from the pools (on average 368 propagules/frog).

The combination of short distance wind and overflow dispersal rates likely explain the dominant species sorting and mass effect patterns observed in the metacommunity in a previous study. Amphibian mediated dispersal was much less important as the Xenopus laevis population was small and migrations very rare.

Based on our own results and available literature we conclude that both vector and propagule properties determine local passive dispersal dynamics of freshwater invertebrates. Accurate knowledge on rates and vectors of dispersal in natural systems are a prerequisite to increase our understanding of the impact of dispersal on ecology (colonisation, community assembly, coexistence) and evolution (gene flow, local adaptation) in fragmented environments.
\end{abstract}

Increased fragmentation of natural habitat stimulated interest in the study of dispersal as a means for (re)colonisation of distant habitat patches and as a vital driver maintaining genetic exchange between isolated populations (Clobert et al. 2001, 2004, Bullock et al. 2002).

Passive overland dispersal of freshwater invertebrates has been the subject of a considerable amount of literature (Bilton et al. 2001, Okamura and Freeland 2002, De Meester et al. 2002, Bohonak and Jenkins 2003). Yet the relative importance of recognised natural dispersal vectors (water, wind and animals) in different types of aquatic habitats is still not well understood. A variety of approaches has been used to study passive dispersal. Despite their popularity, indirect measurements using genetic markers (Rousset 2001, Raybould et al. 2002) or stable isotopes (Caudill 2003) are usually insufficient to grasp the often complex dispersal dynamics of species (Bossart and Prowell 1998). A direct way to investigate the integrated effect of dispersal vectors is to observe colonisation of new water bodies (Maguire 1963, Jenkins 1995, Louette and De Meester 2005) with the option to selectively allow access of some animal vectors (Cáceres and Soluk 2002, Cohen and Shurin 2003, Allen 2007). This approach, however, is only practically possible for small water bodies and provides valuable information on the feasibility of dispersal (effective dispersal or colonisation) but little information on its extent and frequency (Bilton et al. 2001). A method to directly assess dispersal ability and rate is to intercept propagules during transport. Jenkins and Underwood (1998) successfully used wind socks to capture wind dispersing rotifers. Brendonck and Riddoch (1999) measured limited short range wind dispersal of eight Anostraca resting eggs using sticky traps mounted on the rock surface within a cluster of temporary rock pools. In a similar rock pool system Vanschoenwinkel et al. (2008) intercepted 850 airborne propagules from 17 invertebrate taxa at a height of $1.5 \mathrm{~m}$ using wind socks placed in the field during one month. Waterways in general are efficient dispersal pathways for 
aquatic invertebrates, facilitating the rapid spread of invasive species (Shurin and Havel 2002) and mediating gene flow between connected populations (Michels et al. 2001b, Hulsmans et al. 2007). Michels et al. (2001b) showed that, in a cluster of connected ponds, genetic distances of a Daphnia ambigua metapopulation corresponded with distances through connections, rather than geographic distance. High dispersal rates of the fairy shrimp Branchipodopsis wolf $i$ through eroded channels that overflow after heavy rains also corresponded with high levels of gene flow amongst neighbouring temporary pools (Hulsmans et al. 2007). Finally temporary connections can also facilitate dispersal between lentic and lotic systems as was shown by Havel et al. (2000) and by Frisch et al. (2005), who found that riparian wetlands are efficiently colonised by zooplankton during floods. Ample anecdotal evidence has furthermore accumulated regarding the importance of different animal vectors (reviewed in Bilton et al. 2001) including mainly waterbirds (reviewed in Figuerola and Green 2002) but also amphibians (Bohonak and Whiteman 1999) and aquatic insects (Bohonak 1999).

Most of the studies mentioned above, however, focussed on one vector in one particular study system and overlooked several potential complicating factors.

For instance, to demonstrate zoochorous dispersal it does not suffice to verify whether animal life stages survive digestion under lab conditions (Lopez et al. 2002) or whether they successfully attach to vectors. Other factors such as retention time (Charalambidou and Santamaría 2002) as well as migration behaviour of the vector (Bohonak and Whiteman 1999, Green and Figuerola 2005) should be taken into account. In addition, water flow through channels and overflows may be spatially and temporally variable and so may source communities (Van de Meutter et al. 2006). Wind dispersal, in turn, is affected by the availability of propagules and the presence and direction of prevailing winds (Vanschoenwinkel et al. 2008). As a result we cannot yet make generalisations about the total frequency of passive dispersal in natural aquatic habitats or about the relative contribution of different vectors. Different studies have argued that invertebrate communities in isolated aquatic habitats such as ponds and pools are excellent examples of natural metacommunities (i.e. communities connected by dispersal) (Cottenie et al. 2003, Kolasa and Romanuk 2005). However, different metacommunity models fundamentally differ in the amount of dispersal assumed (Holyoak et al. 2005). To test applicability of different metacommunity perspectives, quantification of dispersal is therefore an essential prerequisite.

In this study, we have quantified passive dispersal of temporary rock pool invertebrates in a direct way in order to compare the relative importance of different vectors (water, amphibians and wind) and link local dispersal dynamics to the structure of the invertebrate metacommunity which is described in Vanschoenwinkel et al. (2007). Finally, we discuss vector and propagule properties that may impact the intensity, frequency and scale of local passive dispersal interactions.

\section{Material and methods}

\section{Study site}

The study site consists of a horizontal rock ledge situated at the summit of the Korannaberg mountain $\left(28^{\circ} 51^{\prime} 13^{\prime \prime} S\right.$, $\left.27^{\circ} 13^{\prime} 51^{\prime \prime} \mathrm{E}\right)$ in the eastern part of the Free State Province in South Africa (Fig. 1). The ledge holds a series of 36 rock pools as well as a larger number of smaller depressions and rock cracks which can periodically hold water after rains, ranging from a few days for ephemeral pools and rock cracks up to several months for larger rock pools. For a more detailed description of the geology and hydrology of the pools we refer to Vanschoenwinkel et al. (2007). Vegetation on the study site is patchy and restricted to shallow depressions in the sandstone bedrock that contain soil and consists mainly of succulents, grasses and small shrubs (max height of $40 \mathrm{~cm}$ ). Compared to permanent water bodies, potential animal dispersal vectors on the Korannaberg are scarce. Water birds are absent and passerine birds and large terrestrial vertebrates such as baboons, porcupines and cattle have only very rarely been spotted near the rock pool cluster. At the start of the rainy season (October-November), when temperatures rise and pools fill up for the first time, some pools are colonised by the African clawed frog Xenopus laevis.

\section{Dispersal quantification}

\section{Water-born dispersal}

Eroded channels occur between twelve pool pairs (7-6, 1314, 15-14, 16-14, 17-18, 18-19, 19-28, 23-24, 27-28, 3132, E12-31, E4-29) (Fig. 1) and transport water after heavy rains. Connections are mainly asymmetric (source-sink). In previous years very rarely a symmetric connection (temporary connection of non flowing water) occurred between pool pairs 24-23, 27-28, 31-32 and 7-6 when both pools were completely filled. Such connections were not observed during the study period. We have measured asymmetric dispersal between eight pool pairs (13-14, 15-14, 16-14, 17-18, 18-19, 19-28, E12-31, E4-29). To measure hydrochorous dispersal the water in each channel was guided through a central plastic cup lined with $64-\mu \mathrm{m}$ mesh by means of clay dams (Fig. 2) during three consecutive rainfall events (8 October, 19 October and 14 November) in the 2005-2006 rainy season. All overflow traps were placed in the field on 5 October. Influx of wind blown propagules in dry cups was avoided by thoroughly rinsing the cups prior to rainstorms (announced by cloud formation). Cups were removed and transported to the lab immediately after overflow events. Cups were thoroughly rinsed with $70 \%$ ethanol and samples were checked for propagules under a stereo microscope.

We tested whether morphometric characteristics of the source pool and channel influenced the amount of dispersing propagules. Channel length, width and fall, and basin depth and surface area of the source pool were measured and used as predictors in multiple regression models (Statistica 7.0). The number of dispersing propagules was $\log (\mathrm{x}+1)$ transformed to comply with model assumptions. As the three overflow events differed in the preceding amount of rainfall, we tested whether the average number of 

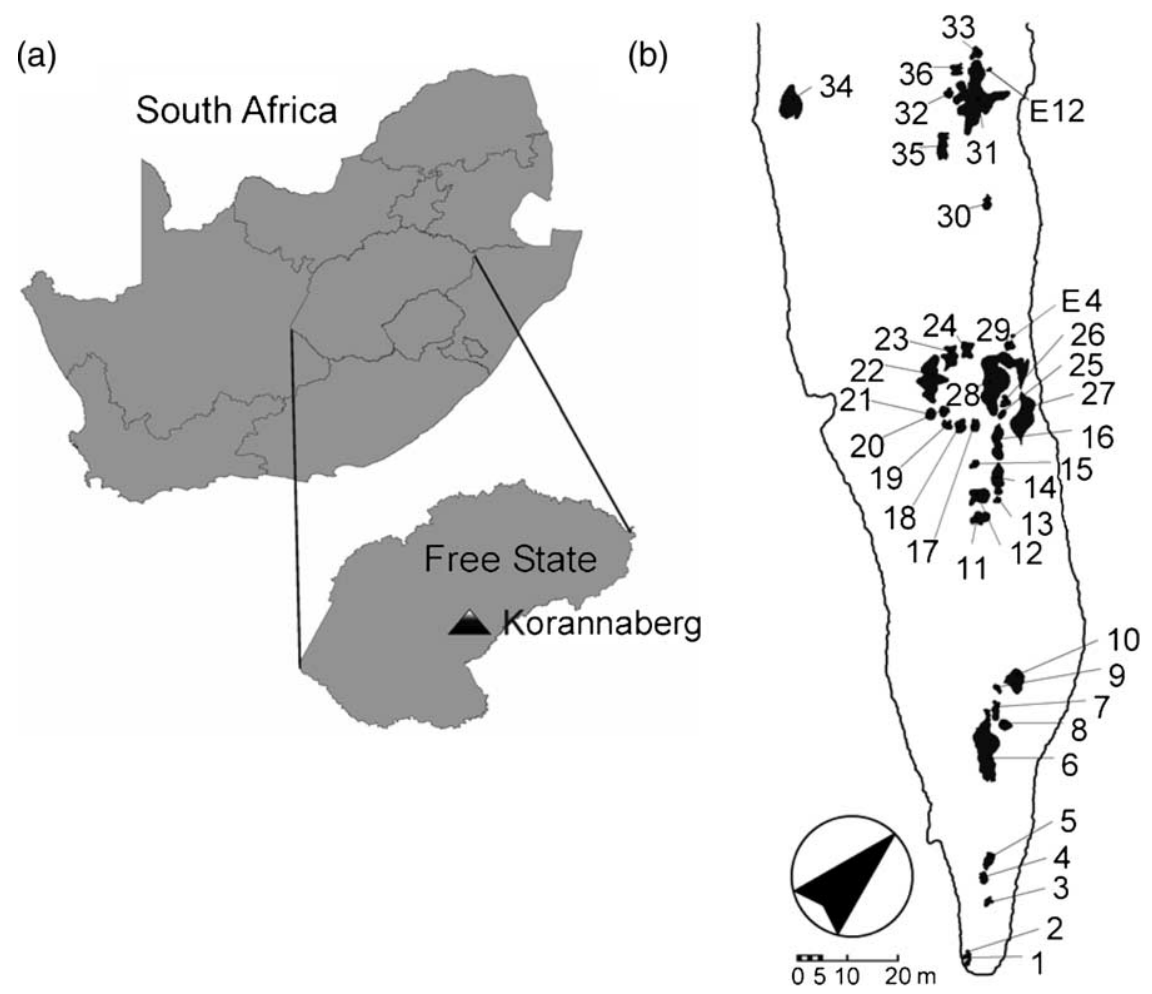

Figure 1. (a) Location of the Korannaberg mountain in South Africa and (b) overview of the lay out of different pools (black) on the study site. All pools are located on a single rock ledge (outline) near the mountain summit.

dispersing propagules differed among overflow events. A non parametric Kruskal-Wallis ANOVA was used as the parametric assumption of homogeneity of variance was not fulfilled.

Finally, using a daily water balance model that makes use of historic climate data (Vanschoenwinkel et al. unpubl.), we calculated the average yearly number of floodings per channel. Hereby an overflow event was recognised every time the modelled water level exceeded the basin depth of the pool. Based on measured dispersal rates in the studied channels and model predicted overflow frequencies we calculated a rough estimate of the yearly average number of propagules transported per channel.

\section{Wind dispersal}

Wind dispersal was quantified using $83(30 \times 30 \mathrm{~cm})$ cardboard surfaces ("sticky traps") coated with ca $2 \mathrm{~mm}$ layer of Tangletrap insect glue (Tanglefoot company)

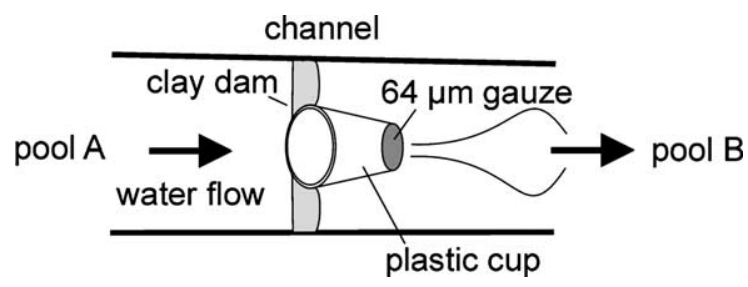

Figure 2. Schematic diagram illustrating the experimental setup used to measure hydrochorous dispersal through channels (overflow trap). All components including the clay dam and the plastic cup lined with fine gauze are indicated. placed in the field during one month (21 July until 21 August) in the 2006 dry season. The dry season in central South Africa lasts from April until September and is characterised by little or no precipitation. During this time period, pools are usually dry or experience very short hydroperiods. Sticky traps were glued directly to the bedrock and uniformly placed over the study site on 21 July (Fig. 4). In order to make sure that all parts of the study site were sampled with equal intensity, in each compartment $(10 \times 10 \mathrm{~m})$ of a grid overlaying a detailed map of the study site, an equal amount of glue traps were placed. We avoided placing traps in pool basins as these would have mainly sampled "within basin" dispersal of eggs.

A number of traps were lost in a thunderstorm in the night of 3-4 August which exceptionally inundated the pools. As the glue was water resistant, influence of this rainfall on the effectiveness of the sticky traps was likely to be minimal. Eighteen pools dried up by 13 August by a combination of evaporation and pumping activities to empty inundated pools (Vanschoenwinkel et al. 2008). On 21 August, after one month, the remaining 63 traps were recovered. The glue surface of each trap was carefully covered with a protective sheet and labelled for transport. All cardboard traps with protective sheets were cut into three strips $(30 \times 10 \mathrm{~cm})$ to facilitate processing. The protective sheet was then stripped from the sticky cardboard and the full surface area of both cardboard and protective sheet was checked for propagules under a stereo microscope. Smaller propagules were isolated and identified under a higher resolution dissection microscope. 
To explicitly test the factors affecting spatial differences in wind dispersal rates we constructed multiple regression models. The distribution of dispersing propagules was not normal but instead matched a Gamma function $\left(\chi^{2}=1.21\right.$; $\mathrm{p}=0.73)$. We therefore performed multiple regression in the generalized linear models module in Statistica 7.0 assuming a gamma distribution of the response (Comtois 2000) and using an inverse power link function to describe the relation between predictor variables and the number of dispersers. Distance to the nearest pool (nearpool) and average distance to the 36 local source pools (isolation) were included as predictor values. Here, only the 36 larger pools usually holding water long enough for macro-invertebrate communities to establish were taken into account. The dominant wind direction on the study site was north, closely followed by winds from the northwest (Vanschoenwinkel et al. 2008). As previous research indicated an effect of dominant wind direction on propagules collected in wind socks (Vanschoenwinkel et al. 2008) we also included the total number of dry pools (pools upwind) and the total area of dry propagule bank (area prop bank upwind) upwind of each sticky trap in our analysis. For the construction of these two variables, every pool that was dry at least during part of the study period (21 July21 August 2006) was regarded as a dry pool. To investigate whether vegetation influences local wind dispersal dynamics, the presence of any vegetation (grasses, mosses, small shrubs) (vegcover) between a sticky trap and potential source pools upwind was also included as a binary variable.

In order to visualise spatial wind dispersal patterns, the exact position of the sticky traps around the study pools was reconstructed in a GIS environment (Arc GIS 8.2). For each sticky trap graduated circles were used to visualise the amount of dispersing propagules caught. To extrapolate wind dispersal rates over the entire study site, we multiplied the average yield/trap (propagules $\mathrm{m}^{-2}$ ) with the total area of the rock ledge $\left(7400 \mathrm{~m}^{2}\right)$, assuming that each part of the study site was sampled with equal intensity. Due to large variation and non-normal (long tailed) distribution of the number of intercepted propagules among traps we calculated a geometric mean which is more appropriate for this type of data than an arithmetic mean (Sokal and Rohlf 1995) and applied a bootstrap procedure (1000 bootstraps with replacement of cases) in order to derive estimates of the standard error and the $95 \%$ confidence interval of the calculated mean. Bootstrapping analysis was performed making use of freeware bootstrap functions (Academic Technology Services Statistical Consulting Group, <http://www.ats. ucla.edu/stat/R/library/bootstrap.htm $>$ ) implemented in R (R Development Core Team 2008).

\section{Amphibian mediated dispersal}

From 1 October until 30 November 2005 all 36 pools were checked daily for frogs and the number of individuals were counted. Over the entire study period frogs were only observed in the three deepest pools with longest hydroperiods (pool 22 [maximum 2 frogs], pool 28 [maximum 2 frogs] and pool 31 [maximum 5 frogs]) where they also reproduced. Observations in the 2005-2006 and 20062007 rainy seasons confirmed that frogs were limited to these pools. In order to investigate whether frogs can act as dispersal vectors for local invertebrate taxa, nine Xenopus laevis were caught (two from pool 22 on 28 October, five from pool 31 on 9 November and two from pool 28 on 24 November 2005). Ectozoochoric dispersal was not explicitly investigated in this study as we were unable to intercept any frogs during migrations. As frogs generally dug into the sediment during capture, collected specimens were thoroughly washed with filtered $(22 \mu \mathrm{m})$ pool water to remove any attached propagules. The collected frogs were kept in a bucket with filtered pool water for $24 \mathrm{~h}$. The following day, frogs were returned into their respective pools and their faeces was filtered over a $64 \mu \mathrm{m}$ gauze and collected in a sample vial on $70 \%$ ethanol. Invertebrate propagules and adults were isolated in the laboratory and identified under a stereo microscope.

\section{Identification of dispersing propagules}

All animal propagules were counted and identified using available information (Anostraca: Brendonck and Riddoch 1997; Bryozoa: Tachet et al. 2000; Cladocera: Flößner 2000, Vandekerckhove et al. 2004; Turbellaria: De Roeck pers. comm.; Oribatidae: Engelbrecht 1975). To be able to assign unknown propagule types to specific taxa, mixed pool sediment from 15 Korannaberg rock pools was incubated in the laboratory in EPA medium (Environmental protection agency 1985) with a conductivity of $20 \mu \mathrm{cm}^{-1}$ and at $20^{\circ} \mathrm{C}$. Problematic taxa (e.g. belonging to Spinicaudata, Copepoda) for which egg morphology could not readily be determined from literature were cultivated separately until egg deposition.

Eggs of Anostraca and Spinicaudata as well as ephippia of Cladocera were identified down to species level. Three types of chydorid ephippia could not be attributed to known species, and were referred to as chydorid morphotypes D, E and F. We distinguished three taxa of adult ostracods: Heterocypris sp., Korannacythere devriesi and one unidentified ostracod morphotype: Ostracoda sp. Copepods were attributed to the orders Harpacticoida or Calanoida. Bryozoan statoblasts were identified to genus level. Resting eggs from Turbellaria and cryptobiotic Nematoda could not be identified to a lower taxonomic level.

We only included propagules or individuals in our analysis that were deemed viable: anostracan and spinicaudatan eggs when a clear embryo popped out when squeezed (method cf. Brendonck and Riddoch 2000a); cladoceran ephippia when they contained intact eggs without external signs of degradation; Oribatidae, Ostracoda and cryptobiotic Harpacticoida when their appendages were intact. For some taxa including e.g. bryozoan statoblasts, viability could not be verified from external structure.

We remark that smaller propagules e.g. resting eggs of ostracods and rotifers and resting stages of Tardigrada and ciliates were certainly present at the study site, as these organisms were observed in the active communities in the pools. However, due to the small size of these propagules (generally $<100 \mu \mathrm{m}$ ) they were not included in this study as they were almost impossible to recover from the glue surfaces and many will have passed through the $64 \mu \mathrm{m}$ mesh of the overflow traps. 


\section{Results}

\section{Water-born dispersal}

Water flow occurred in five of the eight monitored channels (13-14, 15-14, 19-28, E12-31 and E4-29). Dispersing propagules of a total of 11 invertebrate taxa were collected (Table 1). There were no significant differences in dispersal rates among the three monitored overflow events (Kruskal Wallis; $\mathrm{p}=0.082$ ), although rainfall amounts preceding the events were different (Fig. 3). Dispersal rates were significantly higher in channels with shallow source pools as was revealed by multiple regression models. After step by step removal of non significant factors, only the predictor variable "depth of source pool" significantly explained $94 \%$ of variation in the number of overflowing propagules during the study period $(\beta=-0.96 ; \quad D F=6 ; \quad p=$ 0.00007). None of the measured channel properties (length, width, fall) had a significant effect on dispersal rates. Some channels overflow more frequently than others ranging from 6 to 20 times $\mathrm{yr}^{-1}$ (Supplementary material, Table S1). Based on the measured dispersal rates in five channels we estimated that the yearly number of propagules transported per channel ranges from one hundred to several thousands (average: $4088 \pm 3567$; range: $108-8752$ propagules $\mathrm{yr}^{-1}$ ) (Supplementary material, Table S1).

\section{Wind dispersal}

A total of 3462 viable propagules were intercepted, corresponding with an average of $59 \pm 54$ per trap (range 3-267) including 20 taxa (Table 2). The average propagule rain (geometric mean) during the study period of one month was 419 propagules $\mathrm{m}^{-2}(1000$ boot straps: standard error: 54; 95\% confidence interval: 312-524). Extrapolated over the entire study site $\left(7500 \mathrm{~m}^{2}\right)$, a total estimate of 2.85 million propagules rained down during this particular month. Wind dispersal was affected by isolation from source pools. (Fig. 4). Maxima of 3000 propagules $\mathrm{m}^{-2}$ were attained close to source pools $(<1 \mathrm{~m})$, while wind dispersal rates significantly decreased with increasing distance from the nearest source pool. We found no effects of vegetation or dominant wind direction.

Table 1. Overview of invertebrate taxa dispersing through overflows.

\begin{tabular}{llr}
\hline $\begin{array}{l}\text { Overflows } \\
\text { Group }\end{array}$ & Taxon & $\begin{array}{c}\text { No. } \\
\text { propagules }\end{array}$ \\
\hline $\begin{array}{l}\text { Resting eggs } \\
\text { Anostraca } \\
\text { Cladocera }\end{array}$ & $\begin{array}{l}\text { Branchipodopsis tridens } \\
\text { Chydorus sphaericus }\end{array}$ & 1524 \\
& Alona costata & 4 \\
Turbellaria & sp. & 1 \\
Copepoda & Calanoida sp. & 4 \\
Bryozoa & Plumatella sp. & 2201 \\
Adult life stages & & 44 \\
Copepoda & Bryocamptus sp. (Harpacticoida) & 5 \\
Acari & Aquanothrus montanus (Oribatidae) & 253 \\
Insect larvae & Caeculidae sp. & 2 \\
Diptera & Chironomidae (larva) & \\
Coleoptera & Hydroporinae (larva) & 1 \\
\hline
\end{tabular}

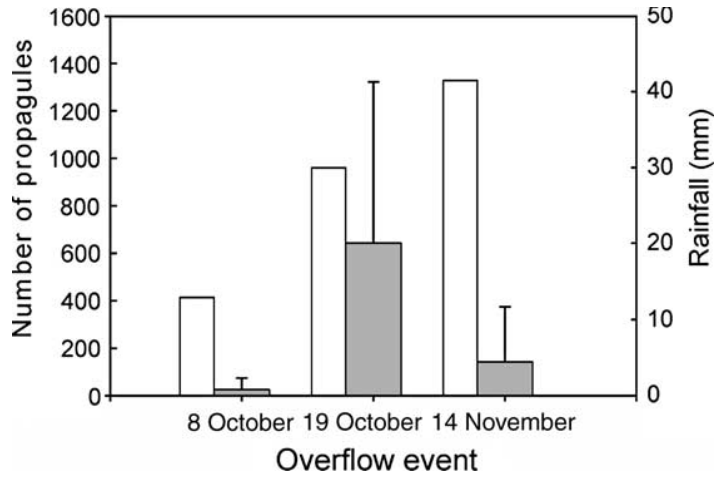

Figure 3. Mean number of intercepted propagules (grey bars) and amount of rainfall (white bars) during different overflow events. Error bars correspond with standard deviations.

After step by step removing non significant predictor variables step by step from multiple regression models, only the distance to the nearest source pool ("nearpool") remained significant. (GLZ: Wald Stat $=9.760, p=$ $0.0018)$.

\section{Amphibian mediated dispersal}

Dispersing propagules (on average 368 propagules/frog) were only retrieved from the faeces of the two frogs caught on 24 November. Viable propagules included four invertebrate taxa, but mainly (99\%) belonged to the spinicaudatan Leptestheria striatoconcha (Table 3). From their initial arrival after inundation of the pools onwards the number of frogs per pool remained constant during the entire study period, except for one likely migration event from pool 31 to 35 . As frogs were not individually marked we cannot entirely exclude the possibility of undetected movements.

Table 2. Overview of invertebrate taxa dispersing by wind.

\begin{tabular}{|c|c|c|}
\hline $\begin{array}{l}\text { Sticky traps } \\
\text { Group }\end{array}$ & Taxon & $\begin{array}{c}\text { No. } \\
\text { propagules }\end{array}$ \\
\hline \multicolumn{3}{|l|}{ Resting eggs } \\
\hline Anostraca & Branchipodopsis tridens & 264 \\
\hline Spinicaudata & Leptestheria striatoconcha & 28 \\
\hline \multirow[t]{7}{*}{ Cladocera } & Macrothrix propinqua & 8 \\
\hline & Chydorus sphaericus & 170 \\
\hline & Alona costata & 242 \\
\hline & Chydorid type D & 2 \\
\hline & Chydorid type $\mathrm{E}$ & 33 \\
\hline & Chydorid type $\mathrm{F}$ & 93 \\
\hline & Simocephalus vetulus & 16 \\
\hline Turbellaria & sp. & 103 \\
\hline Copepoda & Calanoida sp. & 302 \\
\hline Bryozoa & Plumatella sp. & 180 \\
\hline \multicolumn{3}{|l|}{ Adult life stages } \\
\hline Copepoda & Bryocamptus sp. (Harpacticoida) & 400 \\
\hline \multirow[t]{3}{*}{ Ostracoda } & Korannacythere devriesi & 416 \\
\hline & Heterocypris sp. & 28 \\
\hline & sp. & 28 \\
\hline \multirow[t]{2}{*}{ Acari } & Aquanothrus montanus (Oribatidae) & 1070 \\
\hline & Caeculidae sp. & 77 \\
\hline \multicolumn{3}{|l|}{ Insect larvae } \\
\hline \multirow[t]{2}{*}{ Coleoptera } & Dytiscinae (larva) & 1 \\
\hline & Hydroporinae (larva) & 1 \\
\hline
\end{tabular}




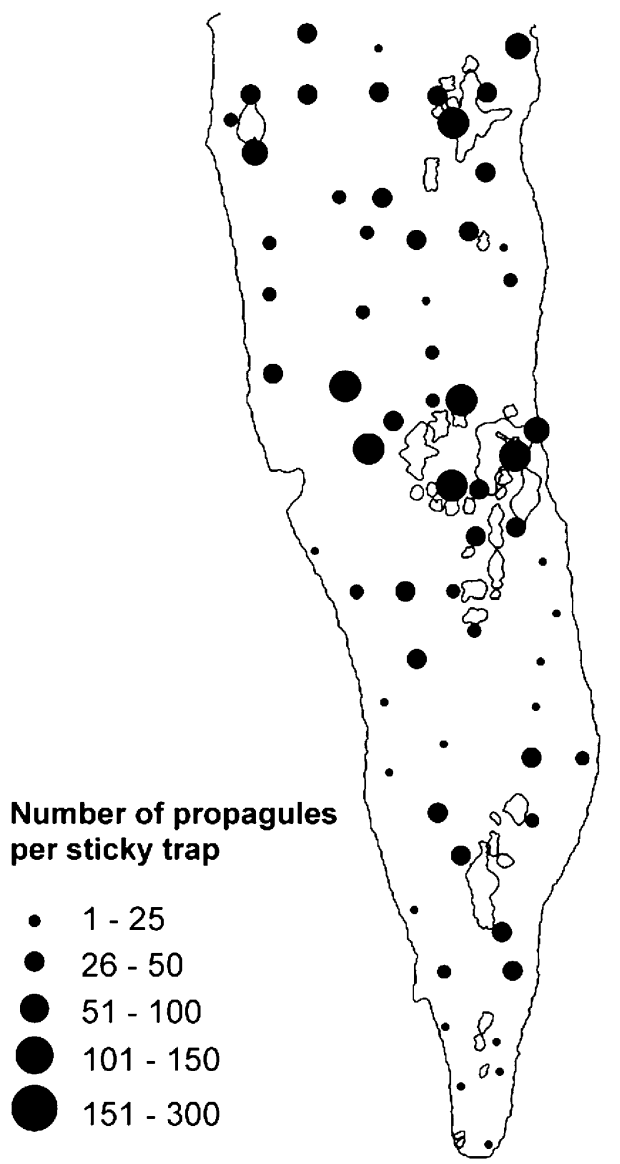

Figure 4. Spatial variation in propagule rain in the Korannaberg rock pool cluster (pools: white; rock ledge: outline). Graduated circles correspond with individual sticky traps. Size is proportional to the amount of wind dispersing propagules captured during one month.

\section{Discussion}

\section{Water-born dispersal}

Water mediated transport of freshwater invertebrates between permanent water bodies is generally considered to be a very efficient dispersal mode (Havel et al. 2000, Michels et al. 2001a, Van de Meutter et al. 2006). In our study, the total number of dispersing propagules transported yearly in overflow channels ranged from hundred to several thousands. That overflows can be efficient dispersal pathways between temporary aquatic habitats was also shown by Hulsmans et al. (2007) for the anostracan

Table 3. Overview of invertebrate taxa retrieved from Xenopus laevis faeces.

\begin{tabular}{llr}
\hline $\begin{array}{l}\text { Amphibians } \\
\text { Group }\end{array}$ & $\begin{array}{c}\text { Xenopus laevis: } \mathrm{n}=9 \text { ) } \\
\text { Taxon }\end{array}$ & $\begin{array}{c}\text { No. } \\
\text { propagules }\end{array}$ \\
\hline Resting eggs & & \\
$\quad \begin{array}{l}\text { Anostraca } \\
\text { Spinicaudata }\end{array}$ & $\begin{array}{l}\text { Branchipodopsis tridens } \\
\text { Leptestheria striatoconcha }\end{array}$ & 20 \\
Adult life stages & & 3288 \\
$\quad$ Copepoda & Bryocamptus sp. (Harpacticoida) & 3 \\
Acari & Aquanothrus montanus (Oribatidae) & 5 \\
\hline
\end{tabular}

Branchipodopsis wolfi. In contrast to an expected close connection between hydrochoric dispersal dynamics and local rainfall patterns and intensity, we found no clear relationship between dispersal rates and amount of precipitation during subsequent observed rainfall events. Dispersal was highest during the second event $(30 \mathrm{~mm}$ rain), although rains preceding the third overflow event were more intense ( $41.5 \mathrm{~mm}$ rain). It is likely that both the number of floating propagules and the number of propagules that can easily be loosened from the propagule bank of the source pools by water action were already exhausted by the third overflow event. Dispersal rates were higher when source pools were shallower and no overflow was observed in three channels fed by relatively deep source pools. In the light of source sink-dynamics, small shallow pools that overflow more frequently and often also hold relatively large resting egg banks (Vanschoenwinkel unpubl.), for this reason, may be better sources for overflow dispersal than larger, deeper ones. None of the measured channel properties (length, width, fall) had a significant effect on dispersal rates, probably due to the fact that channels through which dispersal occurred were all quite similar.

Hydrodynamic characteristics (e.g. buoyancy) of propagules of certain taxa (Anostraca: Brendonck and Riddoch 2000b; Cladocera: Cáceres et al. 2007) may also contribute to the efficiency of hydrochoric dispersal. In that aspect it is illustrative that one of the dominant overflow dispersers in this study was the anostracan Branchipodopsis tridens (Table 1) which produces broods of resting eggs of which a fraction floats (Vanschoenwinkel unpubl.). An overview of different vector and propagule properties that may influence hydrochoric dispersal is given in Table 4.

\section{Wind dispersal}

Wind dispersal is often regarded as an inefficient dispersal mode compared to the directional transport associated with water connections and animals that repeatedly visit water bodies (e.g. water birds) as the chance for a wind dispersing propagule to reach a suitable water body in stead of getting lost in the prevailing terrestrial matrix has been assumed to be relatively low. Nevertheless, recent colonisation studies in artificial mesocosms revealed effective (i.e. resulting in colonisation) wind dispersal over relatively short distances (5-60 m) (Cáceres and Soluk 2002, Cohen and Shurin 2003). Local wind dispersal rates on our study site were high but significantly decreased with distance to source pools, usually already dropping considerably at $10-20 \mathrm{~m}$ from the nearest source pool (Fig. 4). Assuming that all propagules originated from the nearest source can lead to underestimation of dispersal distances (Nathan and MullerLandau 2000). In our study, however, multiple regression models indicated a clear relation with distance to the nearest source and not with average distance to all other pools in the cluster. Therefore, the nearest pool most likely is the dominant source of dispersing propagules.

Contrary to another experiment which used wind socks and was run simultaneously on the same study site (Vanschoenwinkel et al. 2008), no relationship was found between dominant wind direction and wind dispersal rates as measured using sticky traps. However, the relatively long 


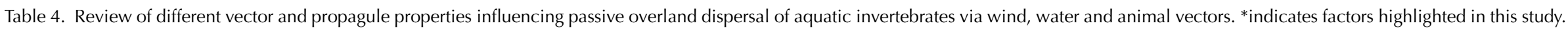

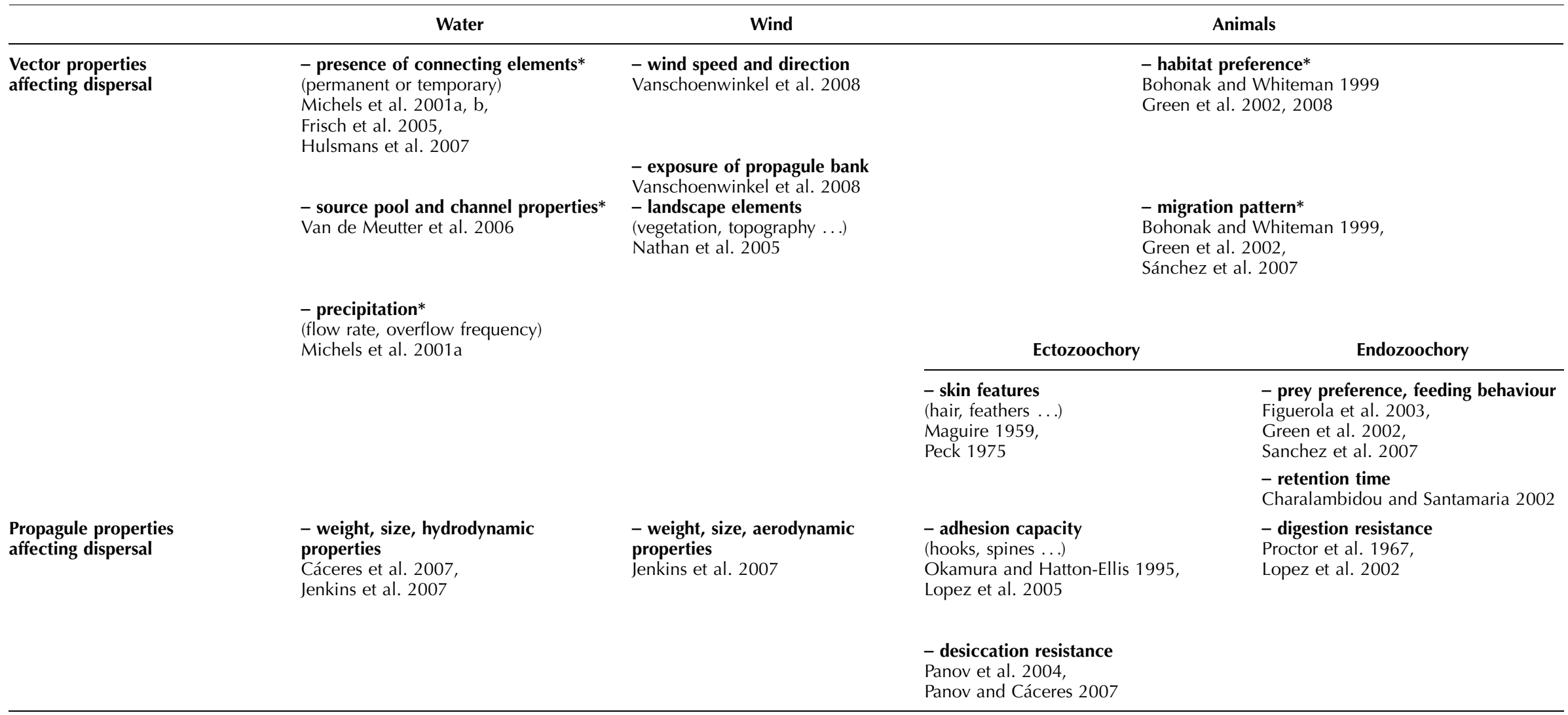


dispersal shadows at the left hand side of the pool clusters in Fig. 4, may be attributed to the dominance of north and northwestern winds. In our current study also more taxa (20 vs 17) were caught compared to the wind sock study, probably due to collection of propagules at ground level in the current assessment. With this approach not only egg rains but also eggs that are transported near ground level by means of saltational movement are intercepted. Differences in the results can also be explained by the higher sample intensity in the current experiment ( 9 windsocks vs 63 sticky traps).

We found no effect of the presence of vegetation between traps and source populations on propagule rain. It is not yet known to what extent landscape elements such as variable topography or vegetation influences wind dispersal. However, recent atmospheric models indicate that depressions in the landscape might act as efficient pick up and deposition places for dispersing propagules (Nathan et al. 2005). Vanschoenwinkel et al. (2008) demonstrated the inhibiting effect of the presence of water in temporary pools on wind dispersal. As a result, wind dispersal from temporary waters is expected to be more frequent than from permanent waters, depending on length of the dry period. Wind dispersal may also be affected by propagule properties such as weight and size (Table 4). In wind dispersed plants, smaller seeds generally disperse further than larger ones (Willson and Traveset 2000). It is unknown to what extent this also applies for invertebrate propagules. In their metaanalysis, Jenkins et al. (2007) found no clear relationship between size and maximum dispersal distance of passively dispersing organisms, suggesting that other propagule properties may be important. Adaptive aerodynamic structures such as the pappose and winged seeds in certain plant groups (Minami and Azuma 2003) are generally lacking in invertebrate propagules, however it has been suggested that even subtle morphological attributes e.g. small pits in the egg shell, might promote aerial transport (Brendonck and Riddoch 1999). An overview of different vector and propagule properties that may influence wind dispersal is given in Table 4.

\section{Amphibian mediated dispersal}

Moore (1971) first proposed the idea that amphibians can act as vectors of freshwater invertebrates after recovering viable fairy shrimp eggs from frog faeces. With exception of studies by Bohonak and Whiteman (1999) and Lopez et al. (1999, 2005), published records of endo - or ectozoochorous dispersal of freshwater invertebrates by amphibians are, however, still rare. We recovered relatively large amounts of viable propagules from faeces of nine Xenopus laevis specimens. Although limited, this observation suggests the potential of this type of dispersal on the study site. Additional laboratory experiments also revealed that at least a fraction of ingested anostracan eggs hatch after gut passage (Vandewaerde unpubl.). Amphibian populations in the Korannaberg rock pools were very small (maximum 9 individuals over three pools) and limited to this particular species. Xenopus laevis is almost exclusively aquatic and only leaves the water when forced to migrate, mostly at night and during rains (Simmonds 1985). This supports the rare observations of frog migrations on our study site. Consequently, the number of propagules transported between pools by amphibians is probably negligible compared to dispersal rates via wind and overflows. Rate and efficiency of invertebrate dispersal mediated by amphibians can furthermore be influenced by various factors which apply for zoochorous dispersal in general (Table 4). Species composition of dispersing propagules, for instance, may strongly depend on habitat (and prey) preference of the vector. Additionally Lopez et al. (2005) showed that some ostracods and annelids can attach to the skin of South American frogs, supporting the possibility of ectozoochoric dispersal with its efficiency being determined by skin features of the vector and adhesion capacity of individual propagules. The feasibility of this type of dispersal, however, could not be verified in our study.

\section{Link between dispersal dynamics and metacommunity structure}

Knowledge on intensity, nature and scale of dispersal for different taxa is, as for populations, also of key importance to better understand the possible impact of dispersal on local community structure and diversity. High dispersal rates may facilitate efficient species sorting processes (Leibold et al. 2004) or even quantitatively impact community dynamics and sustain populations in suboptimal habitats: a pattern known as mass effects (Shmida and Wilson 1985, Amarasekare and Nisbet 2001, Mouquet and Loreau 2002, 2003). Cottenie et al. (2003) found that, in a connected pond system, dispersal could lead to homogenisation of the interacting communities. A comparable pattern of similarities between spatially proximate invertebrate communities occurs in the Korannaberg rock pool metacommunity (Vanschoenwinkel et al. 2007). This spatial pattern, however, was not limited to connected pools. Communities in nearby pools that lacked connecting channels were also more similar, indicating that overflow dispersal alone cannot explain the observed similarities. Both studies concluded that dispersal was not limiting and subscribed the dominance of species sorting processes. Additionally, Vanschoenwinkel et al. (2007) argued that a combination of community homogenisation and reduced richness in connected pools and in pools that lie in close proximity of other pools was indicative for mass effects. Based on the current knowledge we suggest that a combination of short range wind dispersal and overflow dispersal provides the necessary propagule pressure to explain these observed mass effects.

The question may arise how much dispersal is necessary for species sorting or mass effects to occur. Yet, even though dispersal rates may be very high, the effect of dispersal influx on local communities may be negligible when dispersers fail to survive or reproduce in the target patch and dispersal is consequently not translated in corresponding levels of gene flow (De Meester et al. 2002). Consequently, extrapolations from mere dispersal data to expected impact on target populations and communities are dangerous because the link between dispersal dynamics and metapopulation and metacommunity structure is ultimately determined by establishment success, which not only may vary among 
genotypes or species (Louette et al. 2006) but also depends on local physical habitat - (Cottenie and De Meester 2004) and biological characteristics (Shurin 2000, De Meester et al. 2007). Lack of sufficient information on propagule bank densities of different taxa, however, limits our discussion of these aspects in the current paper. Based on the arguments raised we conclude that there are most likely no clear dispersal thresholds that define the operation zone of different metacommunity processes. Quantification of the conversion from dispersal to establishment success would require an experimental approach in which amount of gene flow and/or community assemblage are monitored along gradients of environmental conditions and dispersal rates of selected taxa. Such an experiment, however, would still generate results obtained in a simplified environment and hence would have to be interpreted with care.

\section{Passive dispersal and egg bank budgets}

Given the vast amount of propagules transported, and the relatively low chance of reaching a suitable patch, Vanschoenwinkel et al. (2008) concluded that wind dispersal primarily is a loss factor in the egg bank budget. Although hydrochoric dispersal via permanent water connections can be very efficient (Havel et al. 2000, Michels et al. 2001a), overflowing water and associated propagules also do not always end up in other water bodies. For instance, in our study eroded channels that guide overflowing water from source pools to neighbouring pools only occurred between eight pool pairs. Hence, overflowing water and associated propagules from most other pools were washed of the rock ledge into unsuitable terrestrial habitat instead; a process that may actually lead to egg bank depletion. We conclude that hydrochoric dispersal, like wind dispersal, can be an inefficient costly process, consuming large amounts of propagules. Still, long term benefits of dispersal in unpredictable habitats likely compensate for constant losses, mediating metacommunity dynamics and facilitating persistence of a diverse group of obligate passive dispersers.

\section{General conclusions}

We have shown that, in the studied rock pool metacommunity, local dispersal dynamics were intense and that they were mainly mediated by wind and water. In combination with peak dispersal rates over short distances the measured dispersal rates can explain strong species sorting and mass effects patterns as described in a previous study. Combining our results with a literature review we conclude that the interaction between different vector and propagule properties shapes passive dispersal dynamics in natural aquatic metapopulations and metacommunities.

In general, to better understand underlying processes in population and community development and dynamics in fragmented habitats, we recommend an integrated approach considering most potential dispersal vectors, taking into account various environmental and species properties that may impact dispersal dynamics. Accurate estimates of dispersal rates in natural systems are a prerequisite to better understand the impact of dispersal on ecology (colonisation rate, community assembly, coexistence) and evolution (gene flow, local adaptation) in fragmented environments.

Acknowledgements - Bram Vanschoenwinkel is supported by the Fund for scientific research Flanders (FWO). We thank Danie Vorster, Oom Thys and Annelize Strydom, for logistic support and access to the site, Johannes for meteorological advice and Tom De Bie and Joachim Mergeay for valuable help with the identification of propagules. Weather data were kindly provided by the South African Weather Service. The manuscript was improved by valuable comments from Aline Waterkeyn and Els De Roeck. This research is financially supported by project G.0118.03 of the FWO (Fund for scientific research Flanders).

\section{References}

Allen, M. 2007. Measuring and modeling dispersal of adult zooplankton. - Oecologia 153: 135-143.

Amarasekare, P. and Nisbet, R. M. 2001. Spatial heterogeneity, source - sink dynamics, and the local coexistence of competing species. - Am. Nat. 158: 572-584.

Bilton, D. T. et al. 2001. Dispersal in freshwater invertebrates. - Annu. Rev. Ecol. Syst. 32: 159-181.

Bohonak, A. J. 1999. Effect of insect-mediated dispersal on the genetic structure of postglacial water mite populations. - Heredity 82: 451-461.

Bohonak, A. J. and Whiteman, H. H. 1999. Dispersal of the fairy shrimp Branchinecta coloradensis (Anostraca): effects of hydroperiod and salamanders. - Limnol. Oceanogr. 44: 487-493.

Bohonak, A. J. and Jenkins, D. G. 2003. Ecological and evolutionary significance of dispersal by freshwater invertebrates. - Ecol. Lett. 6: 783-796.

Bossart, J. L. and Prowell, D. P. 1998. Genetic estimates of population structure and gene flow: limitations, lessons and new directions. - Trends Ecol. Evol. 13: 202-206.

Brendonck, L. and Riddoch, B. J. 1997. Anostracans (Branchiopoda) of Botswana: morphology, distribution, diversity and endemicity. - J. Crust. Biol. 17: 111-134.

Brendonck, L. and Riddoch, B. J. 1999. Wind-borne shortrange egg dispersal in anostracans (Crustacea: Branchiopoda). - Biol. J. Linn. Soc. 67: 87-95.

Brendonck, L. and Riddoch, B. J. 2000a. Egg bank dynamics in anostracan desert rock pool populations (Crustacea: Branchiopoda). - Arch. Hydrobiol. 148: 71-84.

Brendonck, L. and Riddoch, B. J. 2000b. Dispersal in the desert rock pool anostracan Branchipodopsis wolfi (Crustacea: Branchiopoda). - Crustac. Issues 12: 109-118.

Bullock, J. M. et al. (eds) 2002. Dispersal ecology. - Blackwell.

Cáceres, C. E. and Soluk, D. A. 2002. Blowing in the wind: a field test of overland dispersal and colonization by aquatic invertebrates. - Oecologia 131: 402-408.

Cáceres, C. et al. 2007. Variation in ephippial buoyancy in Daphnia pulicaria. - Freshwater Biol. 52: 313-318.

Caudill, C. C. 2003. Measuring dispersal in a metapopulation using stable isotope enrichment: high rates of sex-biased dispersal between patches in a mayfly metapopulation. - Oikos 101: 624-630.

Charalambidou, I. C. and Santamaría, L. 2002. Waterfowl as endozoochorous dispersers of aquatic organisms: a review of experimental evidence. - Acta Oecol. 23: 165-176.

Clobert, J. et al. (eds) 2001. Dispersal. - Oxford Univ. Press. 
Clobert, J. et al. 2004. Causes, mechanisms and consequences of dispersal. - In: Hanski, I. and Gaggiotti, O. E. (eds), Ecology, genetics and evolution of metapopulations. Elsevier, pp. $307-$ 336.

Cohen, G. M. and Shurin, J. B. 2003. Scale-dependence and mechanisms of dispersal in freshwater zooplankton. - Oikos 103: 603-617.

Comtois, P. 2000. The gamma distribution as the true aerobiological probability density function (PDF). - Aerobiologia 16: $171-176$.

Cottenie, K. and De Meester, L. 2004. Metacommunity structure: synergy of biotic interactions as selective agents and dispersal as fuel. - Ecology 85: 114-119.

Cottenie, K. et al. 2003. Zooplankton metacommunity structure: regional vs. local processes in highly interconnected ponds. - Ecology 84: 991-1000.

De Meester, L. et al. 2002. The monopolization hypothesis and the dispersal-gene flow paradox in aquatic organisms. - Acta Oecol. 23: 121-135.

De Meester, L. et al. 2007. Genetic composition of resident populations influences establishment success of immigrant species. - Oecologia 153: 431-440.

Engelbrecht, C. M. 1975. New ameronothoid (Oribatidae, Acari) taxa from the republic of South Africa and the islands Gough and Marion. - Navors. Nas. Mus. Bloemfontein 3: 53-72.

Figuerola, J. and Green, A. J. 2002. Dispersal of aquatic organisms by waterbirds: a review of past research and priorities for future studies. - Freshwater Biol. 47: 483-494.

Figuerola, J. et al. 2003. Passive internal transport of aquatic organisms by waterfowl in Donana, south-west Spain. - Global Ecol. Biogeogr. 12: 427-436.

Flößner, D. 2000. Die Haplopoda und Cladocera (ohne Bosminidae) Mitteleuropas. - Backhuys Publ.

Frisch, D. et al. 2005. Diversity of floodplain copepods (Crustacea) modified by flooding: species richness, diapause strategies and population genetics. - Arch. Hydrobiol. 162: 1-17.

Green, A. J. and Figuerola, J. 2005. Recent advances in the study of long-distance dispersal of aquatic invertebrates via birds. - Divers. Distrib. 11: 149-156.

Green, A. J. et al. 2002. Implications of waterbird ecology for the dispersal of aquatic organisms. - Acta Oecol. 23: 177-189.

Havel, J. E. et al. 2000. Diversity of crustacean zooplankton in riparian wetlands: colonization and egg banks. - Aquat. Ecol. 34: 63-76.

Holyoak, M. et al. 2005. Metacommunities: a framework for large-scale community ecology. - In: Holyoak, M. et al. (eds), Metacommunities: spatial dynamics and ecological communities. Univ. of Chicago Press, pp. 1-31.

Hulsmans, A. et al. 2007. Direct and indirect measures of dispersal in the fairy shrimp Branchipodopsis wolf indicate a small scale isolation-by-distance pattern. - Limnol. Oceanogr. 52: 676684.

Jenkins, D. G. 1995. Dispersal limited zooplankton distribution and community composition in new ponds. - Hydrobiologia 313/314: 15-20.

Jenkins, D. G. and Underwood, M. O. 1998. Zooplankton may not disperse readily in wind, rain, or waterfowl. - Hydrobiologia 388: 15-21.

Jenkins, D. G. et al. 2007. Does size matter for dispersal distance? - Global Ecol. Biogeogr. 16: 415-425.

Kolasa, J. and Romanuk, T. O. 2005. Assembly of unequals in the unequal world of a rock pool metacommunity. - In: Holyoak, M. et al. (eds), Metacommunities: spatial dynamics and ecological communities. Univ. of Chicago Press, pp. 233-236.

Leibold, M. A. et al. 2004. The metacommunity concept: a framework for multi-scale community ecology. - Ecol. Lett. 7: 601-613.
Lopez, L. C. S. et al. 1999. Frogs and snakes as phoretic dispersal agents of bromeliad ostracods (Limnocytheridae: Elpidium) and annelids (Naididae: Dero). - Biotropica 31: 705-708.

Lopez, L. C. S. et al. 2002. Bromeliad ostracods pass through amphibian (Scinaxax perpusillus) and mammalian guts alive. - Hydrobiologia 485: 209-211.

Lopez, L. C. S. et al. 2005. Phoretic behaviour of bromeliad annelids (Dero) and ostracods (Elpidium) using frogs and lizards as dispersal vectors. - Hydrobiologia 549: 15-22.

Louette, G. and De Meester, L. 2005. High dispersal capacity of cladoceran zooplankton in newly founded communities. - Ecology 86: 353-359.

Louette, G. et al. 2006. Establishment success in young cladoceran communities: an experimental test. - Limnol. Oceanogr. 51: 1021-1030.

Maguire, B. 1959. Passive overland transport of small organisms. - Ecology 40: 312.

Maguire, B. 1963. The passive dispersal of small aquatic organisms and their colonization of isolated bodies of water. - Ecol. Monogr. 33: 161-185.

Michels, E. et al. 2001a. Zooplankton on the move: first results on the quantification of dispersal in a set of interconnected ponds. - Hydrobiologia 442: 117-126.

Michels, E. et al. 2001b. Geographical and genetic distances among zooplankton populations in a set of interconnected ponds: a plea for using GIS modelling of the effective geographical distance. - Mol. Ecol. 442: 1929-1938.

Minami, S. and Azuma, A. 2003. Various flying modes of winddispersing seeds. - J. Theor. Biol. 225: 1-14.

Moore, W. G. 1971. Effect of long-time storage and other factors on the hatchability of Streptocephalus seali eggs. - Am. Zool. 13: $1257-1354$.

Mouquet, N. and Loreau, M. 2002. Coexistence in metacommunities: the regional similarity hypothesis. - Am. Nat. 159: 420-426.

Mouquet, N. and Loreau, M. 2003. Community patterns in source-sink metacommunities. - Am. Nat. 162: 544-557.

Nathan, R. and Muller-Landau, H. C. 2000. Spatial patterns of seed dispersal, their determinants and consequences for recruitment. - Trends Ecol. Evol. 15: 278-285.

Nathan, R. et al. 2005. Long-distance biological transport processes through the air: can nature's complexity be unfolded in-silico? - Divers. Distrib. 11: 131-137.

Okamura, B. and Hatton-Ellis, T. 1995. Population biology of bryozoans - correlates of sessile, colonial life-histories in freshwater habitats. - Experientia 51: 510-525.

Okamura, B. and Freeland, J. R. 2002. Gene flow and the evolutionary ecology of passively dispersing aquatic invertebrates. - In: Bullock, J. M. et al. (eds), Dispersal ecology. Blackwell, pp. 194-216.

Panov, V. E. and Cáceres, C. E. 2007. Role of diapause in dispersal of aquatic invertebrates. - In: Alekseev, V. et al. (eds), Diapause in aquatic invertebrates: role for ecology, physiology and human uses. Springer, pp. 187-195.

Panov, V. E. et al. 2004. Role of diapause in dispersal and invasion success by aquatic invertebrates. - J. Limnol 63(Suppl 1): 56-69.

Peck, S. B. 1975. Amphipod dispersal in the fur of aquatic mammals. - Can. Field Nat. 89: 181-182.

Proctor, V. W. et al. 1967. Dispersal of aquatic organisms viability of disseminules recovered from intestinal tract of captive killder. - Ecology 48:672.

Raybould, A. F. et al. 2002. Inferring patterns of dispersal from allele frequency data. - In: Bullock, J. M. et al. (eds), Dispersal ecology. Blackwell, pp. 89-110.

R Development Core Team 2008. R: a language and environment for statistical computing. - $\mathrm{R}$ Foundation for Statistical Computing, Vienna, Austria, <http://www.R-project.org $>$. 
Rousset, F. 2001. Genetic approaches to the estimation of dispersal rates. - In: Clobert, J. et al. (eds), Dispersal. Oxford Univ. Press, pp. 18-28.

Sanchez, M. I. et al. 2007. Transport of brine shrimps via the digestive system of migratory waders: dispersal probabilities depend on diet and season. - Mar. Biol. 151: 1407-1415.

Shmida, A. and Wilson, M. V. 1985. Biological determinants of species diversity. - J. Biogeogr. 12: 1-20.

Shurin, J. B. 2000. Dispersal limitation, invasion resistance and the structure of pond zooplankton communities. - Ecology 81: 3074-3086.

Shurin, J. B. and Havel, J. E. 2002. Hydrologic connections and overland dispersal in an exotic freshwater crustacean. - Hydrobiologia 4: 431-439.

Simmonds, M. P. 1985. African clawed toad survey. - British Herpetological Society Bulletin No. 13.

Sokal, R. R. and Rohlf, F. J. 1995. Biometry: the principles and practice of statistics in biological research, 3rd ed. - W. H. Freeman.

Download the Supplementary material as file E5442 from $<$ www.oikos.ekol.lu.se/appendix $>$.
Tachet, H. et al. 2000. Invertébrés d'Eaux Douces. Systématique, biologie, écologie. - CNRS Editions.

Vandekerckhove, J. et al. 2004. Use of ephippial morphology to assess richness of anomopods: potentials and pitfalls. - J. Limnol. 63: 75-84.

Van de Meutter, F. et al. 2006. Lotic dispersal of lentic macroinvertebrates. - Ecography 29: 223-230.

Vanschoenwinkel, B. et al. 2007. The role of metacommunity processes in shaping invertebrate rock pool communities along a dispersal gradient. - Oikos 116: 1255-1266.

Vanschoenwinkel, B. et al. 2008. Any way the wind blows, frequent wind dispersal drives species sorting in ephemeral aquatic communities. - Oikos 117: 125-134.

Willson, M. F. and Traveset, A. 2000. The ecology of seed dispersal. - In: Fenner, M. (ed.), Seeds: the ecology of regeneration in plant communities, 2 nd ed. CABI Publ. pp. $85-110$. 